\title{
Mário de Andrade en Klaxon De joven estudioso a crítico erudito: la construcción de un proyecto intelectual
}

\author{
Mário de Andrade in Klaxon \\ From young scholar to scholarly critic: the construction of an intellectual project
}

Karina Vasquez

Doutora em Ciências Sociais e Humanas Professora do Departamento de Ciencias Sociales da Universidad Nacional de Quilmes e do Departamento de Filosofía da Facultad de Filosofía y Letras

kvasquez@gmail.com

Resumo: En este artículo nos proponemos analizar la participación de Mário de Andrade en Klaxón (1922-1923), la primera y probablemente la más conocida de las revistas modernistas. Esta revista, junto a la Semana de Arte Moderna, representa -en la canonización posterior de un movimiento fuertemente asociado a la intelectualidad paulista- el evento fundador del modernismo, el primer emprendimiento editorial propio de un grupo que venía formándose desde 1917 y mostraba aspiraciones fuertes de intervención en la esfera cultural brasileña. El análisis de la asidua participación de Mário de Andrade en la revista nos permitirá mostrar cómo este autor se construyó a sí mismo en la figura del crítico, al mismo tiempo que contribuyó significativamente a moldear los rasgos característicos de este proyecto editorial. Palavras-chave: Mário de Andrade, Modernismo, Intelectuales, Revistas

\begin{abstract}
In this article we analyze the participation of Mário de Andrade in Klaxon (1922-1923), the first and probably the best known of modernist magazines. This magazine, together with Modern Art Week, represents -in the subsequent canonization of a movement strongly associated with Paulista intellectuality - the founding event of modernism, the first venture formed by a group itself which had been developing since 1917 and showed strong intentions for intervention in the Brazilian cultural sphere. The analysis of the regular participation of Mário de Andrade in the magazine will allow us to show how the author built himself in the figure of the critic, while significantly contributed to shaping the unique features of this publishing project.

Keywords: Mário de Andrade, Modernism, intellectuals, cultural magazines.
\end{abstract}

Culturales. 


\section{Introducción}

A la hora de reflexionar sobre la participación de Mário en Klaxon, surgen algunos interrogantes que vale la pena subrayar: ¿cómo fue posible para este joven catedrático del Conservatorio, que no contaba con una obra publicada ni con una columna regular en algún diario de prestigio o amplia circulación, convertirse de pronto en "a grande figura intelectual do mensario" (BRITO, 1972: 11)? ¿Qué estrategias provocaron que el Mário ignoto de 1917, con un primer libro de poesía que prefirió relegar al olvido, sea reconocido por Manuel Bandeira en 1922 como una "figura dominadora em nossas letras, de uma inteligência e de uma cultura magistrais" (MORAES, 2000: 74), y cuáles fueron los contenidos que viabilizaron este reconocimiento?

Nuestra hipótesis es que el joven tímido de 1921 que, a diferencia de Oswald, no se había destacado por el carácter provocativo de sus intervenciones en los diarios, y que -según su propio testimonio- había sido arrastrado a la Semana de Arte Moderno por el entusiasmo de los otros (ANDRADE, 1974: 232), hace de Klaxon su propio bastión. Apareciendo con regularidad en las crónicas y reseñas, exponiendo sus poemas, pero sobre todo apropiándose de las secciones marginales de la revista, Mário consigue ser el centro de esta y operar así una primera transformación de su propia figura: de joven estudioso aficionado a los libros a crítico erudito. Pero el conocimiento de los autores nuevos, de las revistas contemporáneas, de los acontecimientos relevantes y remotos de la escena artística internacional no solo autoriza su prosa, es una marca que Mário transfiere a la revista con el propósito explícito de educar al público, un público que implícitamente incluye a los amigos y colegas que participan de la revista, y aquellos otros intelectuales que se muestran indiferentes u hostiles ante este emprendimiento.

En un ambiente marcado por la hegemonía cultural de las instituciones y los circuitos bohemios de Río de Janeiro, Mário tratará de consolidar al grupo paulista para insertar su disidencia en esa tradición. Construye así, aceleradamente, su propia reputación defendiendo la de Klaxon, una reputación que no va a poner el énfasis exclusivamente en las obras -porque gran parte de esas obras modernistas todavía no habían sido escritas o no estaban publicadas-, sino más bien en un ethos en el que resalta la figura del crítico-escritor cuyo saber lo inclina al reconocimiento de las marcas particulares de la sensibilidad contemporánea en la ciudad moderna y cosmopolita de San Pablo. Esta figura se inscribe, se produce y se reinventa a sí misma en el contexto de un 
grupo de amigos, es decir, de una red de sociabilidad en la que entran en juego tanto la expresión de valores comunes como las relaciones afectivas.

\section{Consideraciones generales sobre la revista}

El primer número de Klaxon aparece el 15 de mayo de 1922 y, como señala Silva Brito (1972: 1), no trae indicación de director, secretario o redactor-jefe. La revista no aclara cuáles son los miembros de "a redação", en parte porque se propone como órgano de una colectividad intelectual, de un grupo de amigos - como Antônio Carlos Couto de Barros, Tácito y Guilherme de Almeida, Mário de Andrade, Sérgio Milliet, Oswald de Andrade, Rubens Borba de Moraes y Luis Aranha - que se reúnen en la oficina de Tácito de Almeida o de Couto de Barros para trabajar en la revista antes de salir a recorrer los bares, confiterías y cabarets paulistas. Klaxon es el producto de una sociabilidad intensa, que se expande en circuitos informales como el atelier de Tarsila o las recorridas por la ciudad en el famoso Cadillac verde de Oswald. Con respecto a esto, es importante enfatizar dos cuestiones:

1) La colectividad intelectual que se identifica con Klaxon no se restringe al grupo de amigos que hacen la revista: esta se extiende para abarcar a Menotti Del Picchia, Candido Motta Filho, Plinio Salgado; jóvenes como Sérgio Buarque de Holanda -que aparece desde el primer número como corresponsal en Río de Janeiro--; amigos como Manuel Bandeira -que comienza a colaborar en el número 3-; el grupo de Río -Graça Aranha, Ronald de Carvalho y Renato de Almeida- y los artistas que colaboran con el extratexto -Victor Becheret, Di Cavalcanti, Zina Aita, Anita Malfatti, Yan de Almeida, John Graz, Tarsila de Amaral y Villa-Lobos-.

2) Muchas de las colaboraciones firmadas con seudónimo o de "a redação" no fueron escritas por el "grupo" en general, sino que corresponden a la autoría de Mário de Andrade. Una mirada de conjunto sobre la revista muestra la significativa asiduidad de la colaboración de Mário (LARA, 1972: 105).

Del número 1 al 8-9, la revista presenta dos secciones claramente diferenciadas. La primera es la sección principal presentada sin título al inicio de cada sumario, que exhibe colaboraciones en verso y prosa (por lo general, de ficción) en portugués, francés, y alguna en español e italiano. En esta sección encontramos a Mário en el número inicial con el Manifiesto-Programa titulado Klaxon, con los poemas "São Pedro", "Poema” y 
"Poema Abulico" publicados respectivamente en los números 4, 6 y 8-9, y con el artículo "Farauto" que abre el número 7. Pero donde realmente se destaca la presencia de Mário es en la segunda sección, titulada Chronicas, en la que aparecen ensayos breves de índole crítica sobre música, literatura, pintura y cine. Las reseñas de libros y los comentarios de revistas aparecen allí bajo el subtítulo de Livros e Revistas, junto con la curiosa subsección Luzes e Refracções, hecha de pequeños comentarios críticos y jocosos, donde, como subraya Cecilia de Lara (1972: 17), predomina la defensa de las posiciones modernistas y la contestación a la crítica académica. Además de las crónicas sobre música - "Pianolatria" ( $\left.\mathrm{N}^{\circ} 1\right)$, “Guiomar Novaes (1)" ( $\mathrm{N}^{\circ}$ 2), “Guiomar Novaes" ( $\left.\mathrm{N}^{\circ} 3\right)$, "Música descriptiva" ( $\left.\mathrm{N}^{\circ} 4\right)$, "Música" ( $\mathrm{N}^{\circ}$ 6), "Música” $\left(\mathrm{N}^{\circ} 7\right)$-, escribe algunos comentarios sobre cine; trece de las veinte reseñas que aparecen en el conjunto de la revista, y toda la subsección fija de Luzes e Refracções de los números 1 al 6. Es decir, en buena parte de los números, la sección Chronicas está casi integralmente escrita por Mário. Y esto es relevante, porque si la primera sección se propone exhibir o mostrar las nuevas producciones contemporáneas (con un claro predominio de la poesía), es en la segunda donde encontramos más claramente el esfuerzo por explicar, argumentar, discutir y convencer sobre aquello que se propone como novedad. Muchas de estas notas no están firmadas por Mário, algunas aparecen con iniciales que han sido identificadas como suyas, y otras como anónimas: se ve aquí el deseo de componer un grupo, el gesto de escamotear la firma para afirmar la presencia de un grupo.

En la presentación-manifiesto, Mário comienza posicionando a Klaxon en relación con el período inmediatamente anterior:

A lucta começou de verdade em princípios de 1921 pelas colunas do "Jornal de Commercio" e do "Correio Paulistano". Primeiro resultado: "Semana de Arte Moderna" -espécie de Conselho Internacional de Versalhes. Como este, a Semana teve sua razão de ser. Como elle: nem desastre, nem triumpho. Como elle: deu fructos verdes. Houve erros proclamados em voz alta. Pregaram-se ideias inadmissíveis. É preciso refletir. É preciso esclarecer. É preciso construir. D'ahi, KLAXON” (A Redação [Mário de Andrade], 1922a: 1). ${ }^{1}$

\footnotetext{
${ }^{1}$ En todas las citas, se ha conservado la ortografía original de la fuente.
} 
Asignar a la Semana de Arte Moderno el papel de una "espécie de Conselho Internacional de Versalhes" subraya la voluntad de dar por concluida esa etapa de "lucha". Mário inscribe a Klaxon en una línea de continuidad con los debates llevados a cabo en 1921 y con la Semana de Arte Moderno, pero acentúa la intención de distanciarse de esos acontecimientos: sin duda, ambos esfuerzos habían contribuido a otorgar visibilidad a estos jóvenes, pero esta misma visibilidad -ligada al moderado escándalono había permitido ni la reflexión grupal en torno a principios comunes, ni el esclarecimiento del público. Tres meses después de la Semana de Arte Moderno, Mário subraya que Klaxon se ofrece como tribuna para estas tareas, enfatizando al comienzo y al final de su manifiesto la necesidad de abrir paso a un momento constructivo. Este rasgo se acentúa en la sección siguiente, "Esthetica", que pretende exponer -de forma muy condensada- los "principios" desde los cuales se sostiene el tipo de intervención que la revista pretende generar:

KLAXON sabe que a vida existe. E, aconselhado por Pascal, visa o presente. KLAXON não se preocupará de ser novo, mas de ser atual. Essa é a grande lei da novidade.

KLAXON sabe que a humanidade existe. Por isso é internacionalista. O que não impede que, pela integridade da pátria, KLAXON morra e seus membros brasileiros morram.

KLAXON sabe que a natureza existe. Mas sabe que o moto lírico, produtor da obra de arte, é uma lente transformadora e mesmo deformadora da natureza. KLAXON sabe que o progresso existe. Por isso, sem renegar o passado, caminha para diante, sempre, sempre. O campanile de São Marcos era uma obra prima. Devia ser conservado. Cahiu. Reconstrui-lo foi uma erronia sentimental e dispendiosa $-\mathrm{o}$ que berra diante das necessidades contemporâneas (A Redaçcão [Mário de Andrade], 1922: 1-2. Grifos do original).

Principalmente en esta sección, Mário retoma algunos momentos del debate anterior, y lo encapsula, es decir, ya no presenta estas posiciones bajo la forma de "polémica": lo "actual" no aparece aquí recortado contra la "inactualidad" del medio cultural paulista, el internacionalismo no entra en conflicto con el nacionalismo, el progreso no pretende renegar del pasado y sí del sentimentalismo -que vuelve a aparecer hacia el final en conexión con el rechazo del "romanticismo sentimental e technico"- y 
se asocia con la psicología experimental a la hora de reclamar "libertad" frente a los preconceptos y las reglas del parnasianismo. Como sostiene Jardim de Moraes (1988: 224-225), este manifiesto revela cierta fascinación por los procesos de modernización urbana -el raciocinio, la rapidez, el deporte, la ciencia- en la cual estos nuevos "engenheiros"-que no van a "derrumbar campanile algum"- esperan encontrar los materiales para construir la "era do riso e da sinceridade".

\section{Mário, constructor del internacionalismo de Klaxon}

En la presentación-manifiesto, Mário insiste en definir la renovación que el grupo propone como un esfuerzo de actualización, que aspira incorporar al Brasil a debates y perspectivas contemporáneas que predominan en la escena internacional. De allí, que sin renegar del pasado, Klaxon explicita y ostenta ese internacionalismo: desde el primer número, la revista presenta a Charles Baudouin -por entonces, un profesor de filosofía, amigo de Romain Rolland- como representante en Suiza, y a Roger Avermaete -un escritor belga que en 1919 funda la revista Lumière que devendrá también editorial-como representante en Bélgica; comenta los sumarios de algunas prestigiosas revistas extranjeras, como la Nouvelle Revue Française, L'esprit noveau, la revista marsellesa Le criée y la española Cosmópolis; y en cada número, la primera sección de la revista presenta colaboraciones en las que el portugués alterna con el francés, y ocasionalmente, con el español y el italiano.

Klaxon se exhibe cosmopolita: esta pequeña "familia" paulista está al tanto de lo que acontece en la escena internacional, y se sitúa a sí misma en referencia a ese marco mucho más amplio, que supera el circuito Río-San Pablo. Esta entronización de la escena internacional al interior de la propia revista con frecuencia va a ser puesta al servicio de la tarea de explicar y legitimar tanto los contenidos nuevos que este emprendimiento propone poner en circulación, como la forma de sociabilidad que lo sostiene.

Así, ya en el primer número, en la sección de Luzes e Refracções, Mário se va a tomar el trabajo de explicitar muy sutilmente el lazo que une a este grupo de amigos y justifica la defensa mutua: 
Pelo 'Emporium' de Fevereiro o passadista Piccoli ataca a arte austríaca moderna. E, mais uma vez, se revolta contra as associações de elogio mutuo... Por quanto tempo ainda se repetirão tolices tais? Ha afinidades eletivas.

Seria possível ao Snr. Brecheret preferir a companhia do Snr. Ximenes ao convívio do Snr. Maestrovic? O elogio mutuo, derivado da mutua compreensão, é uma sinceridade orgulhosa e justa. Cada um de nos traz uma Academia Brasileira de Letras no espírito. E as eleições são feitas sem pedidos de voto, nem visitas. São nobres.” (M. de A., 1922: 15).

Como observamos en la cita, Mário retoma un comentario de una revista extranjera, publicada en Bérgamo, Italia, Emporium, rivista mensuale ilustrata d'arte e di cultura; y menciona el comentario de un articulista desconocido, Piccoli. Al calificarlo como "passadista" ya desde la primera frase "brasileiriza" la escena, la remite al contexto local, en el que ese círculo de amigos, que mutuamente se presentan al público y se defienden en los periódicos locales, parece -a los ojos de esa "parentada" simbolistaparnasiana, que manifestaba las mayores reticencias frente a estos "futuristas"simplemente una "asociación de elogio mutuo".

Y Mário, que con frecuencia va a ser uno de los más preocupados en cubrir las reticencias y las críticas en un manto de elogios, justifica su propia actitud: si el elogio se apoya en la comprensión mutua, es decir, en una empresa común, es "sinceridad orgullosa y justa". Podría interpretarse que al mencionar que "cada um de nós traz uma Academia Brasileira de Letras no espírito", Mário está abogando tanto por la legitimidad de esa Academia del espíritu, como por el compromiso estable de sostener la comprensión de los compañeros a los que aparece ligado por "afinidades electivas". Ese tipo de estabilidad que se asienta en la institución -y opera mediando frente a conflictos, roces y disputas internas por el reconocimiento, que afectan a los individuos- por definición, no existe en un grupo de amigos; pero al invocarla, Mário sostiene como aspiración -para los de dentro y fuera de Klaxon- la solidez de un grupo que se apoya no en el exterior de la institución, sino en la "nobleza" que proviene del corazón, del "yo interior" del que brota la sinceridad.

En los números siguientes, en la misma sección de Luzes e Refracções, Mário menciona, retoma y procura descalificar sin indirectas los comentarios negativos que suscita el proyecto, especialmente aquellas críticas que aparecen en las revistas y diarios de Río. 
Así, por ejemplo, en el número 2, Mário debate:

João de Talma, lá d' $O$ Imparcial, não sabe fazer uso dos seus dentes. Contemplando KLAXON, em vez de sorrir (de prazer ou ironia, pouco importa), arreganha-os com exagerado ódio. Deante da capa tão alegremente moderna da revista confessa `ter a impressão de que se trata da engenhosa reclame de um purgativo enérgico'. Ainda bem que ele o perceba: para ficarmos livres dessa alimentação pesada que há 30 ou 40 anos os nossos atuais acadêmicos vêm cozinhando para nós (e que ainda satisfaz o paladar complacente e o estomago de ferro do Sr. Talma), só mesmo com o uso constante de tais medicamentos (LUZES E REFRACÇÕES, 1922a: 17).

En realidad, João de Talma del diario $O$ Imparcial no fue el único en criticar la portada de la revista: también Lima Barreto, en una crónica de A Gazeta, y Manuel Bandeira -en este caso por carta a Mário- presentan sus objeciones contra el nombre o la tapa de la revista. ¿Por qué este detalle habría de ser relevante? Porque toda la revista apuesta a la diferencia que produce un diseño cuidado, que incluye extratextos de artistas defendidos por el grupo (Becheret, Anita Malfatti, Tarsila, Di Cavalcanti, entre otros), y tanto en la portada como en los dos anuncios que brevemente aparecen en la revista - de "Coma Lacta" y "Guarana espumante"- se trata de resaltar esa diferencia asociando la publicidad gráfica a la poesía moderna. El problema es que esa bohemia, que producía al mismo tiempo poemas parnasianos y caricaturas satíricas, ya había incursionado en la publicidad: de hecho, Bastos Tigre había establecido una empresa publicitaria en 1913. Y le contestan como profesionales de ese incipiente mundo publicitario: esa portada no se entiende, no está bien hecha si parece la de una revista de propaganda de automóviles americanos (en la versión de Lima Barreto) o el "réclame de um purgativo energico" (en la de João de Talma). Es decir, lo que ese tipo de crítica desliza solapadamente es que esa portada tan "alegremente moderna" es, en realidad, de amateurs, que no conocen el oficio -ni el de la publicidad, ni el de la escritura. Y aquí Mário responde, esquivando la crítica profesional en torno a la buena o mala composición de la portada, pero sin dejar de acentuar qué es lo que está, por así decirlo, del "otro lado" de esos jóvenes amateurs: los pesados académicos, cuya producción -la misma desde hace treinta o cuarenta años, en la imagen que presenta el texto- ya resulta indigerible.

Sin embargo, Mário enfrenta otras críticas mucho más fuertes en los números siguientes. Cabe resaltar aquella que -despegándose del tradicionalismo- tendía a 
desprestigiar a estos jóvenes calificándolos como meros imitadores de "novidadeirices" que ya ni siquiera eran tales en el contexto europeo. Posiblemente, versiones de esa crítica circulaban ya antes de la Semana de Arte Moderna, a propósito de la apropiación del "futurismo".

En el número 3, Mário escribe una extensa crónica, titulada $O$ homenzinho que não penso, en la que responde ácidamente a un articulista anónimo de la revista carioca O mundo literario, quien afirmaba que el manifiesto de Klaxon era apenas una repetición sintética del de Marinetti y acusaba a la revista de representar "aquillo que tanto horroriza os seus talentosos creadores: um passadismo", en parte por hacerse eco de un manifiesto "que já vem creando bolor ha não menos de quinze annos". Mário desmiente enfáticamente la similitud entre ambos manifiestos, abordando parágrafo a parágrafo las discordancias con Marinetti: no es ni en la lucha, ni en el amor al peligro, y sobre todo, no es la destrucción del pasado, en donde pretende situarse la actualidad de Klaxon. Y, continua el joven paulista, "se em outras coisas aceitamos o manifesto futurista, não é para segui-lo, mas por compreender o espírito de modernidade universal" (ANDRADE, 1922a: 10-11).

Y quizás temiendo que esta observación pasara desapercibida en el conjunto de ácidas réplicas dirigidas contra $O$ homenzinho que não penso, vuelve sobre el mismo tema en un parágrafo de Luzes e Refracçoes:

Houve quem dissesse que copiamos Papini, Marinetti, Cocteau... Entre copiar e seguir a diferença é grande. O snr. Ronald de Carvalho ainda há pouco, pelo "Jornal" de 21 de abril passado, justificava os snrs. Álvaro Moreyra, Manoel Bandeira, Ribeiro Couto por se terem educado na escola dos franceses. Ora KLAXON vai mais além. Não se educa só na escola dum Cocteau francês e dum Papini italiano, mas também lê a cartilha dum Uidobro espanhol, dum Blox russo, dum Avermaete belga, dum Sandburg americano, dum Leigh inglês. E porquê não Looz um austríaco, ou Becher um alemão? Dizer de KLAXON que copiamos um, quando seguimos a muitos é querer diminuir a grandeza dum vôo que persegue a rota indicada pelo 1922 universal. KLAXON não copia Papini nem Cocteau, mas representando às vezes tendências que se aparentam às dêsse grande italiano e dêsse interessante francês, prega o espírito da modernidade, que o Brasil desconhecia (LUZES E REFRACÇÕES, 1922b: 14. Grifos do original). 
Tal como ha señalado Jardim de Moraes (1988: 227-229), en esta primera etapa del modernismo, "o espirito de modernidade" constituye un orden universal o un suelo común, cuyo acceso no requeriría aún la construcción de la propia particularidad. En el discurso de Mário, no se trata de copiar, sino de seguir tendencias en las cuales se manifiesta el "espíritu de la época" que se realiza simultáneamente en distintas partes del mundo, como lo prueba no solo el amplio arco de colaboradores de Klaxon, sino también la "velocidade vertiginosa" de la renovación poética que afecta a lugares tan distantes de la tradición occidental como Japón (HORIGOUTCHI, 1922: 14). Por esta misma época, entre abril y mayo de 1922, Mário había concluido la redacción de A escrava que não é Isaura (Discurso sobre algumas tendências na poesia modernista), cuya próxima aparición -como edición de Klaxon - fue anunciada en el número 4 de la revista. El proyecto de crear una editorial anexa a la revista no se concretó, y Mário tuvo que soportar varias demoras hasta finalmente publicar el libro en 1924, aclarando en el postfacio que ese libro ya no lo representaba por entero y que más bien se trataba de una "fotografia tirada em Abril de 1922" (ANDRADE, 1960: 297). En este ensayo, que pretende ser un estudio explicativo de la poesía modernista, encontramos el mismo principio: poemas de Luis Aranha, Cendrars, Apollinaire, Cocteau, Manuel Bandeira, Menotti Del Picchia, Sérgio Milliet, Picabia, Aragon, Tristan Tzara, son analizados como partes de un mismo movimiento que, con distintas inflexiones, realiza la necesidad de traducir "nuevas sensaciones" y expresar el espíritu de la época. La expresión de la actualidad admite diversas realizaciones, pero para reconocerlas y apreciarlas es imprescindible el estudio y la profundización de las diversas líneas que constituyen ese "espírito da época". De hecho, uno de los leitmotiv más usados por Mário contra aquellos que atacan a Klaxon pasa por poner en primer plano que el articulista en cuestión "no conoce" obras, autores o revistas en los que está "actualidad” estaría circulando. Así, por ejemplo, “dispara” contra $O$ homenzinho que não penso, anónimo que conocía o identificaba la autoría de Mário en la presentación-manifiesto de la revista:

Mas o tão anônimo quanto falso articulista conhece o Ivan Goll do manifesto Zenith? Conhece a Cocteau de 'Le Coq et l'Arlequin`? Satie dos `Cahiers d’un Mamifere'? e outros tantos "sujeitos sem importância em virtude e letras" modernas? Se os conhecera veria em meu estilo uma adaptação literária da rapidez vital contemporânea (ANDRADE, 1922a: 10-11). 
La misma recomendación, esta vez formulada en un tono más jocoso, se extiende a Lima Barreto, cuyo enorme prestigio como cronista y novelista contrastaba con el recelo que el lenguaje coloquial de su prosa generaba entre los poetas parnasianos. Era un personaje con el cual hubiera sido posible encontrar coincidencias o preocupaciones comunes. Sin embargo, la recepción de Barreto de Klaxon reitera contra estos jóvenes un mecanismo de deslegitimación ya conocido: la de limitar la actualidad de la revista y del grupo al "descubrimiento de Marinetti", para explicar luego que ni este ni aquellos representan ninguna novedad. Ante esta crítica, en el número 4 de la sección de Luzes e Refracções, Mário le sugiere,

(...) amigavelmente tomamos a liberdade de lhe dar um conselho: Não deixe mais que os rapazes paulistas vão buscar ao Rio edições da Nouvelle Revue, que, apesar de numeradas e valiosíssimas pelo conteúdo, são jogadas como inúteis em baixo das bem providas mesas das livrarias cariocas. Não deixe também que as obras de Apollinaire, Cendrars, Epstein, que a Livraria Leite Ribeiro de há uns tempos para cá (dezembro, não é?) começou a receber, sejam adquiridas por dinheiros paulistas. Compre êsses livros, snr. Lima, compre êsses livros!” (LUZES E REFRACÇÕES, 1922c: 17).

Podríamos considerar que, ante Klaxon, diversas voces se levantan desde la "familia bohemia", insistiendo en calificar a estos jóvenes como provincianos que imitan novedades atrasadas en Europa. Y Mário responde una y otra vez, acentuando el carácter cosmopolita, de quien pretende situarse en un arco amplio de la escena internacional cuyo centro ignora a Río-, pudiendo precisar no uno, sino varios ejes de referencia.

A diferencia de sus opositores o de todos aquellos que -como escribe Mário"pelo jornal ou no segredo nem sempre honesto das orelhas amigas vivem a entoar contra nós madrigaes, sivantes e sátiras do mal-dizer", Klaxon estudia y no "se educa só na escola dum Cocteau francês e dum Papini italiano, mas também lê a cartilha dum Uidobro espanhol, dum Blox russo, dum Avermaete belga, dum Sandburg americano, dum Leigh inglês" (KLAXON, 1922b: 14). Y, sin duda, Mário estudia y sabe indicar con precisión cuándo y qué libros, revistas y autores llegaban a la famosa librería Leite Ribeiro.

Y es la exhibición de este saber, adquirido en el estudio, en la que Mário se apoya para defender a sus amigos, reaccionando contra la crítica negativa que se cierne sobre la 
novela Os Condenados, de Oswald de Andrade, publicada en el transcurso de 1922. Así, en la sección de Luzes e Refracções del número 5, afirma:

Em nota de 20 de agosto passado, fallando sobre "Os Condemnados" de Oswaldo de Andrade, affirma o "O Jornal de Commercio" que os modernistas ficaram "damnados" com o aparecimento desse livro de "velha escolha". Engana-se o articulista. (...) Chamar de "velha escola" à simultaneidade, ao processo cinematográphico, ao expressionismo e principalmente ao princípio esthetico do único plano intelectual da "Trilogia do Exilio" é desconhecer a "velha escola" e o sentimento de modernidade (LUZES E REFRACÇÕES, 1922d: 15).

Tema sobre el que vuelve a insistir en la misma sección del número 6:

É interessante observar a ignorância dos críticos, cujos vaticínios cream ou destroem reputações. Ignorância crassa. Ignorância revoltante acompanhada sempre de uma impertinência cômica e de uma erudição de almanach. Então quando falam dos modernos, esses senhores de óculos prudentes e calvícies affirmativas perdem completamente o pé. Assim é que, criticando o romance de Oswaldo de Andrade, um homem muito acatado, após haver passeado várias rasteiras na lógica e embrulhado em phrases cabelludas um punhado de ideias contradictórias, diz que o nosso colaborador só se salva pelas qualidades das velhas escolas que ainda se percebem nelle: simultaneidade, synthese etc.!!! Que pândego! (LUZES E REFRACÇÕES, 1922e: 16).

Posiblemente, Mário tampoco fuera un admirador entusiasta de Os condenados: de hecho, él-que hizo muchas de las reseñas de la revista- no se encarga de la reseña de este libro, y en el último número, en una reseña que funciona a modo de "balance del modernismo", pareciera que es $O$ Homem e a morte de Menotti Del Picchia la obra que a sus ojos destaca en la producción de 1922, punto que suscitó una fuerte pelea con Oswald, tema sobre el que volveremos más adelante. Por el momento, interesa destacar que Mário defiende a Oswald amparado en un extenso conocimiento de una escena internacional actual que le permite discernir los matices que separan a ese "velha escola" -en la que se había formado un amplio espectro de la "familia bohemia"- de la modernidad presente. Contra el caricaturista Hermes Fontes y otros de aquella misma escuela, que no están 
preocupados por una diferenciación precisa entre lo viejo y lo nuevo, Mário discrimina y se muestra como el que puede discernir rasgos específicos allí donde los otros -en la imagen que construye- apenas juntan ideas contradictorias. Y, para eso, Mário estudia, y Klaxon, con él, y se educa no solo en la escuela de un Cocteau o Papini, sino que también lee a españoles, ingleses, americanos, austríacos y alemanes, y con ellos "se mueven en las mismas aguas de la modernidad", una modernidad que requiere ser aprendida (en libros, revistas y obras de arte contemporáneas), pero también enseñada. "Quero ver se esclareço um pouco a compreensão da gente que lê" (MORAES, 2000: 73), escribe Mário en una carta de octubre de 1922 a Manuel Bandeira. Pocos años después, esta vocación ya aparece explícita: en una carta a Prudente de Moraes de 1925, discutiendo A escrava, señala: "Minha arte nem é bem arte porquê vive arreada dum mundo de preocupações interessadas não pra mim o que seria justificável porêm pros outros. Não faço arte, ensino. Pode ser que ensine mal porêm a intenção é de ensinar bem” (KOIFMAN, 1985: 122).

Si, para 1925, Mário ya no duda incluso en hacer la apología de esa vocación de maestro, en 1922 esta aparece como la contracara del joven que estudia. A diferencia de sus contrincantes, Mário conoce, y conoce porque estudia, y en Klaxon estudia con el propósito de enseñar - a propios y extraños- cuáles son las coordenadas en las que se afirman esas "afinidades electivas".

\section{La figura del crítico en las crónicas sobre música: la revuelta contra el romanticismo}

La inflexión didáctica de Mário se destaca en sus crónicas sobre música, escritas con el propósito de educar el gusto del público en general, pero también rectificar sutilmente lo que consideraba errores y/o exageraciones de la etapa anterior. Así, en la primera nota de esta sección, titulada "Pianolatria", Mário vuelve sobre la famosa polémica en torno de Carlos Gomes (1836-1896), el más importante compositor brasilero de estilo romántico, que había gozado de un considerable éxito en Europa. Su ópera $O$ Guarany (1870), basada en una novela de José de Alencar, había sido representada en toda Europa y en Estados Unidos. En el primer tiempo del modernismo, Carlos Gomes era visto como la mayor gloria de la cultura tradicional brasilera, blanco de ataques e impugnaciones. La anterior polémica había tenido como protagonista principal a Oswald de Andrade, que en un violento y provocativo artículo despachaba su artillería contra el 
compositor de Campinas, con el propósito de enfatizar por contraste la modernidad de Villa-Lobos: “Carlos Gomes é horrível. Todos nós o sentimos desde pequeninos. Mas como se trata de una glória de família, engolimos a cantorolice toda do Guarani e do Schiavo, inexpressiva, postiça, nefanda" (Apud NAVES, 1998: 38).

Esta actitud, que apuesta a la confrontación y el escándalo, se distingue claramente del tono de Mário en sus crónicas de Klaxon. En efecto, la referencia a Carlos Gomes está inserta en un artículo que apunta a convencer al público de que "apenas uma educação pianística" o "uma tradição pianística" no constituyen signos de una cultura musical adelantada o completa. A esa tradición pianística afincada en San Pablo, opone la tradición del violín, del violoncello y del canto, manifestaciones musicales más completas que el escritor paulista considera desarrolladas en Río. Es decir, no solo se opone a la consideración corriente de que "São Paulo está musicalmente mais adiantado que o Rio", sino que además considera que ese progreso del piano, en detrimento del estudio serio de otros instrumentos, es "uma das causas de nosso atrazo musical". En O violão azul, Santuza Naves (1998: 24) explica cómo el piano va a ser, para estos jóvenes modernistas, el emblema de una tradición romántica que se quiere superar, además de representar al instrumento que se presta como ningún otro a la práctica virtuosa, es decir, al malabarismo exhibicionista y la expresión convencionalizada. Estos temas van a ser desarrollados por Mário en las crónicas siguientes, dedicadas a Guiomar Novaes; por ahora nos interesa subrayar cómo introduce la referencia a Carlos Gomes en el contexto de un artículo que acentúa la insuficiencia de la cultura musical paulista. En efecto, Mário se sirve de otra estrategia, muy diferente a la de Oswald, para impugnar al compositor:

É costume dizer-se que São Paulo está musicalmente mais adiantada que o Rio. E logo a prova: 'Tivemos Carlos Gomes. Temos Guiomar Novaes'. Não ha duvida. O Brasil ainda não produziu músico mais inspirado nem mais importante que o campineiro. Mas a época de Carlos Gomes passou. Hoje sua musica pouco interessa e não corresponde às exigências musicaes do dia nem à sensibilidade moderna. Representá-lo ainda seria proclamar o bocejo uma sensação estética. Carlos Gomes é inegavelmente o mais inspirado de todos os nossos músicos. Seu valor histórico, para o Brasil, é e será sempre imenso. Mas ninguém negará que Rameau é um das mais geniais personalidades da música universal... Sua obra-prima, porém representada há pouco em Paris, só trouxe desapontamento. Caiu. É que o francês, embora chauvin, ainda não proclamou o bocejo sensação estética" (M. de A, 1922a: 8). 
Es evidente que Mário retoma intencionalmente la polémica, con el objetivo de transformar el insulto a la "glória de família" en un razonamiento que aspira a movilizar al público en la búsqueda de una formación musical más amplia, liberada del "preconceito pianístico". Para ello, reconoce que Carlos Gomes no es -como decía Oswald- "horrível", pero su "inégavel” valor aparece desplazado al pasado. La desautorización que supone esta operación es reforzada a través de la comparación con Rameau en Francia: el predominio de la actualidad contra un pasado que ya "não corresponde às exigencias musicaes do dia nem à sensibilidade moderna" (M. de A, 1922a: 8) se afirma sincrónicamente tanto en París como en San Pablo.

En la segunda y tercera crónicas, dedicadas a Guiomar Novaes (1894-1979), Mário va a exponer sutilmente el mismo argumento: esta intérprete representa tendencias inactuales. Pero si ya no era una empresa fácil relegar al pasado las óperas de Carlos Gomes, compuestas en el último tercio del siglo XIX, el caso de Novaes exigía aún mayores precisiones. En efecto, se trataba de una artista joven -prácticamente de la misma edad de Mário -, que gozaba de un considerable éxito internacional, a la que los propios modernistas celebraban y habían convidado a la Semana de Arte Moderna, evento en el que la artista participó con reticencias. A semejanza del procedimiento usado con Carlos Gomes, el análisis de Mário va a sostener el reconocimiento con restricciones: a pesar de sus magníficas cualidades, Novaes no es una artista que pueda educar al público en la sensibilidad contemporánea.

Ya el subtítulo de la primera crónica, "Pianista romántica", anuncia las objeciones que Mário va a desarrollar en los dos artículos, porque como señala Elizabeth Travassos (1997: 29), la eclosión del modernismo va a estar asociada a la crítica al sentimentalismo, propiciado por el romanticismo entendido en sentido amplio. Este va a ser visto como un período que favoreció la exaltación, el descontrol y, por lo tanto, la deformación de los sentimientos; en oposición a la sensibilidad moderna, propia del "homem moderno" y del “espirito moderno", que abogaba por la simplicidad, el coloquialismo, el despojamiento, y -como proclama la presentación manifiesto de Klaxon- "a extirpação das glândulas lacrimaes".

En el inicio del artículo, Mário intenta una comparación entre dos artistas de San Pablo que alcanzaron nivel internacional: Antonieta Rudge Miller y Guiomar Novaes, 
Agradável e fácil seria um paralelo entre ambas. Nada menos trabalhoso do que salientar a antítese violenta que entre elas existe. Uma: carácter severo, tipo clássico, diríamos cerebral; e, por todas essas qualidades dominantes intérprete exacta dos clássicos e dos post-românticos. Outra: pianista romântica na mais total significação do termo, vibratibilidade impressionável à mais fina cambiante da sensação (ANDRADE, 1922b: 13).

Pero esta comparación no puede avanzar, porque Rudge Miller-esposa de Charles Miller, que en la década del '20 dejaría a su marido para convivir con Menotti Del Picchia-, ya no se presenta en conciertos en Brasil ni en el exterior. Entonces, retomando el problema que había planteado en "Pianolatría", Mário ubica el papel de Guiomar Novaes en el contexto de la escena musical paulista:

Estamos ainda em pleno romanticismo sonoro; e Chopin é o soluçante ideal de todas as nossas pianeiras. A senhora Rudge Miller seria o único mestre possível desse auditório; capaz de impor-lhe Debussy e Ravel -músicos que já representam um passado na Europa e que ainda mal são percebidos pela nossa ignara gente. Guiomar Novaes -certamente maior como genialidadenão preenche essa falta. Artista já universal, não pode imobilizar-se neste polo-norte que é o Brasil; e, caracteristicamente romântica, não representaria com eficácia êsse papel de mestre que educa" (ANDRADE, 1922b: 13).

Tanto por la imposibilidad de permanecer en el Brasil debido a sus compromisos internacionales, como por su inflexión romántica, la gran artista no puede, sin embargo, representar con eficacia el papel de maestra del público: ese lugar queda vacante para el crítico, que es Mário de Andrade. Pero si la primera razón no requiere mayores precisiones -la artista viaja y no permanece demasiado tiempo en San Pablo-, también resulta en última instancia irrelevante. Pero Mário sí precisa explicar más exhaustivamente por qué su carácter romántico la inhabilita como "Mestre”. Y aquí, parte de la preferencia que la artista dedica en sus programas a los compositores románticos como Chopin, Shumann y Lizst-, para subrayar que comparte con ellos algo más esencial:

Os românticos, entregues ao delírio de viver pelos sentidos, traduziram, mais do que o próprio eu interior, um eu dos sentidos, si me poderei explicar, um eu livre de controle. Vejo neles uma realização toda sensual, toda exterior. 
Para esses artistas de 1830 o julgamento da inteligência, na criação da obra de arte, realizava-se tão somente sob o ponto de vista da beleza formal. A senhorinha Novaes apresenta, quer interprete Scarlatti, quer Rachmaninoff, as mesmas tendências românticas que acima demostrei. E, embora admirável num estudo de Scriabine, embora atraente numa fuga de Bach, é sempre em Schumann, Listz e especialmente Chopin que atinge sua maior força de expressão. (ANDRADE, 1922b: 14. Grifos do original).

Tanto en el "Prefacio Interesantísimo" de Paulicéia Desvairada como en A escrava que não é Isaura, la aversión al sentimentalismo no excluye la defensa de la sensibilidad: el arte parte del lirismo, de un grito del yo subconsciente o inconsciente que precisa comunicar la sensación recibida. Pero ese lirismo necesita de la crítica y el trabajo de la inteligencia para transformarse en arte. La necesidad de expresión proviene de un más allá de la conciencia, pero para que esta se transforme en una auténtica expresión del yo interior requiere del trabajo de la inteligencia, un trabajo selectivo que no deforma la composición peculiar de lo dado, sino que lo enriquece y lo potencia. En este caso, la crítica al romanticismo sostiene que el ego libre del control de la inteligencia termina desplazando al auténtico yo interior, y el exceso de sensualidad produce pura exterioridad. De ahí que el sentimiento se transforme en sentimentalismo, en exageración cargada de falsedad. En consonancia con esto, en la segunda crónica dedica a Guiomar Novaes, Mário destaca dos aspectos esenciales de la artista como intérprete: "a fantasia exaltada e a sensibilidade que transborda em excessos sentimentais". Y agrega: "Não aponto defeitos. Verifico tendências. Uma tendência pode não ser atual, isso não implica ser defeituosa" (ANDRADE, 1922c: 8).

Aquí vemos el hilo conductor que, desde "Pianolatria" une a Guiomar Novaes con Carlos Gomes: ambos son los músicos más inspirados que Brasil produjo, ambos con sobrado reconocimiento internacional, ambos -por distintas razones-inactuales.

A pesar de que a Guiomar Novaes "no le va bien” - dice Mário- la discreción más serena de los clásicos o el impresionismo intelectual de los modernistas como Debussy, a pesar de que no podía comprender "a caçoada feita a Chopin no primeiro Sarau da Semana de Arte Moderna", sin embargo Mário le reconoce el hecho "a milhor intérprete do romanticismo musical" (ANDRADE, 1922c: 9).

Y este reconocimiento de Novaes va de la mano de la afirmación del lugar del crítico que "verifica tendencias" y explica al público en qué consisten esas tendencias. En 
este sentido, resulta significativa la inclusión -en dos momentos del artículo- de su propia experiencia en un concierto de la artista:

A snha. Novaes partia para os Estados Unidos. Concêrto de despedida. Eu estava no galinheiro. Suava, ensardinhado numa comparsaria boquiaberta, eterna e incondicionalmente entusiasmada ante qualquer interpretação, boa ou má, que saísse das mãos da grande artista. Sensação de mal-estar e desprêso. Mas Guiomar sacudira os ritmos iniciais da peça com uma energia, uma convicção, uma verdade inexcedíveis... O que vi! O que ouvi! (...) Acredito que duas vezes não terei com essa peça a mesma comoção. Eu deposito na glória da snha Novaes a lágrima que nessa noite chorei. É o presente dum homem que não tem pela intérprete nem simpatia nem antipatia. Um homem insensível á glória que a acompanha. Um homem isento de patriotadas que não se orgulha da snha. Novaes ser brasileira porquê considera os grandes artistas, quer criadores, quer intérpretes, seres de que não importa conhecer a nacionalidade, mas aos quais todos nos humanos, devemos ser reconhecidos. Não minha lagrima vai a homenagem dum ser, não sem preconceitos (é coisa extra-humana) mas o mais livre possível de prejuízos sentimentais (ANDRADE, 1922c: 9. Grifos do original).

Aun sudando en el gallinero, el crítico se distingue de aquellos que aplauden incondicionalmente cualquier interpretación. A pesar de todas las restricciones señaladas anteriormente, el reconocimiento de la artista delinea, por contraste, la figura del crítico: la de un hombre en el cual el entendimiento no se deja avasallar ni por el prestigio ya establecido de Novaes (es decir, por la tradición y/o la opinión corriente), ni por prejuicios sentimentales, como el patriotismo. Y, aunque no siente simpatía ni antipatía por la artista, en la imagen que Mário quiere construir tampoco la amistad es un impedimento serio para el ejercicio de esa capacidad crítica. Diferenciándose de Oswald, en una carta a Tarsila de 1923, sostiene:

O Oswaldo é ser feliz. Nasceu iludido com a genialidade. Se lhe digo versos meus, num recanto familiar de Café, goza feliz e sou um gênio. Se é o Menotti, Menotti é um gênio. Se és tu, tu és o gênio. Sei que é sincero. Mas a amizade, de que é tão lindamente prodigo, obumbra-lhe nesses momentos por completo a faculdade crítica. Mas a crítica, também, e mesmo a crítica cheia de reservas, severa, é um ato de amor. (AMARAL, 1999: 74) 
Y esa crítica severa es la que se manifiesta en las otras dos crónicas, en las que trabaja sobre dos figuras totalmente opuestas a Guiomar Novaes: Francisco Mignone (1897-1986) y João de Souza Lima (1898-1982), los dos apenas de paso por la ciudad en 1922 porque gozaban de becas del Pensionato Artístico do Estado de São Paulo para perfeccionar sus estudios en Europa. A diferencia de Novaes, ambos estaban iniciando sus carreras de compositores e intérpretes, inclinándose hacia las preferencias modernistas, no gozaban todavía del prestigio y la atención dispensados a la gran artista. En las respectivas crónicas de Mário, hay un intento de colocar estos nombres en la escena musical paulista, pero sin ahorrar restricciones y reservas.

Así, en el caso de Mignone, después de oír algunos trechos de la ópera $O$ Contractador de Diamantes, destaca una buena impresión general sobre la obra, pero agrega:

Certamente seria o cumulo de má vontade exigir dum músico que apenas inicia sua carreira dotes de originalidade já francamente determinada, bem como especialização de modernismo em quem ainda é estudante e caminha sob as vistas dum professor. Existe porém nos trechos que ouvi aquela chama benéfica, reveladora dos bons artistas de amanhã" (ANDRADE, 1922d: 12$13)$.

Los elogios del artículo -referidos sobre todo al cuadro sinfónico de las danzas brasileras en el segundo acto- terminan celebrando al artista que Mignone será en el futuro, "quando encontrar inteiramente sua personalidade". Es decir, la alabanza de la obra futura esconde mal las restricciones y reservas frente al presente.

Con Souza Lima, la crítica sigue el mismo esquema, quizás acentuado porque retoma una impresión anterior negativa: "Recordava-me do estudante que partira, talentoso, sem duvida (vivem por ahí as dúzias talentos!) bem dirigido, mas fraco, incerto, sem virilidade nem sabedoria" (ANDRADE, 1922e: 11). Esta imagen se transforma en la sorpresa del "Souza Lima de agora", que si bien en su último concierto ha mostrado que se "metamorfoseou-se em Orfeo", no puede, todavía, "domar a las fieras". En un programa extraordinario, pero también fragmentario y dispersivo, Souza Lima se mostró -a juicio de Mário- como "o primeiro intérprete brasileiro que soube quebrar as cadeias do pegajoso sentimentalismo", pero este entusiasmo no le impide subrayar: "Falta-lhe 
maior dose de humanidade, de profundeza, de sensibilidade heroica e trágica. Brilha já, mais ainda não perturba, não revoluciona as almas. (...) Souza Lima é muito moço ainda. Tenho certeza de que adquirirá essa profundeza que lhe carece por agora. E que não adquira, será grande o mal?" (ANDRADE, 1922e: 12).

Y aquí entra el crítico, que enseña al público por qué eso que considera que falta es esencial:

\begin{abstract}
Vou ao concerto para me comover. Não há dúvida. Mas para me comover na ordem artística e não na ordem natural. Misérias da vida, acho-as quotidiamente junto de mim, para, além das minhas ter de chorar as fáceis lagrimas de Chopin, as cóleras de Beethoven, os sarcasmos de Schumann. As comoções de ordem artística sublimam e elevam. Da combinação de sons, que isto é a música (deixemo-nos de complicações metafísicas) nascem dentro de mim comoções ideais, sensações frenéticas, suaves, báquicas ou puras, gráceis ou severas que me fazem vibrar, mas desprendido do mundo. Eis porquê amo Bach e o Beethovem da $1^{\mathrm{a}}$ e $3^{\mathrm{a}}$ fases principalmente. Eis porquê adoro Mozart. Eis porquê gosto dos modernos e do maxixe de Nazareth" (ANDRADE, 1922e: 12. Grifos do original).
\end{abstract}

En medio de todos de los reconocimientos que el artículo sostiene -en el que se destaca la armonía de las cualidades técnicas del joven intérprete, la musicalidad de la ejecución, la superación del romanticismo, etc.-, sin embargo, a los ojos de Mário, este joven, asiduo asistente de las tertulias que Tarsila y Oswald organizaban en París, no consigue todavía producir esa conmoción propiamente artística, que el crítico resalta en el recuerdo del concierto de Novaes.

En las crónicas sobre música, la figura del crítico sobresale en la impugnación del romanticismo de la reconocida intérprete brasilera Guiomar Novaes. Pero frente a aquellos otros jóvenes, compositores e intérpretes cercanos al modernismo y amigos del grupo de Klaxon, se impone también la figura del educador, del pedagogo del público, que así como no está obnubilado por los prejuicios sentimentales del patriotismo a la hora de juzgar a Novaes, tampoco se entrega a un exceso de entusiasmo por lo nuevo. El reconocimiento que expresa hacia estos jóvenes inclinados a la "música modernista" aparece cercado por restricciones, reservas y elogios dirigidos a la obra futura. Así, el profesor del conservatorio encuentra por fin una cátedra que supera los estrechos límites de la institución: sus alumnos son, indistintamente, los músicos y compositores que 
crítica, el público que asiste a los conciertos, y la elite paulista que tiene en sus manos la posibilidad de instrumentar desde el Estado los medios para superar el tan mentado "atraso musical" de la escena cultural paulista.

\section{Mário y la "familia de Klaxon" en las reseñas}

Si bien Mário se jacta de la "crítica severa", ejercida como un acto de amor, y de hecho en las crónicas sobre música su figura aparece revestida de cierta ecuanimidad, que le permite al mismo tiempo hacer reconocimientos y restricciones fuertes, tanto a la gran artista consagrada como a los jóvenes que recién se inician en la orientación modernista; este tipo de distancia no siempre va a predominar en las reseñas.

Desde la primera hasta la última entrega, la revista publicó en total veinte reseñas, trece de las cuales son de la autoría de Mário, firmadas con sus iniciales (M. de A.), o con otras identificadas como propias (LARA, 1972: 69). Cambiar las iniciales es una estrategia que aspira a producir en el lector una sensación de pluralidad, disimulando el claro predominio de la voz de Mário.

La extensión de las reseñas con frecuencia se reduce a un breve comentario que registra la aparición del libro, acompañado de una opinión negativa o positiva sobre la obra. Así, en casos como los de Afranio Peixoto, Hermes Fontes o Martins Fontes médico y poeta parnasiano, amigo de Menotti Del Picchia-, predomina la crítica ácida que con frecuencia no reconoce -a diferencia de lo expresado sobre el música Carlos Gomes- ni siquiera una gloria pasada. En las obras de dichas figuras, en general impugna una tendencia a la repetición de fórmulas gastadas que degenera en decadencia: en Bugrinha señala que Afranio Peixoto aburre al lector repitiendo el esquema de novelas anteriores; en Despertar, Hermes Fontes continua sin ninguna innovación los procedimientos de Apoteosis; y en Arlequinada, Martins Fontes no consigue siquiera destacarse en la producción de versos alejandrinos.

Si en líneas generales es clara la impugnación de las figuras consagradas de la poesía parnasiana, cabe subrayar la apreciación -ambiguamente positiva- que Mário esboza en las reseñas sobre la producción ensayística de figuras que se tornarán representativas de la intelligentsia católica . En efecto, Mário presenta el libro Pascal e a inquietação moderna de Jackson de Figueiredo, editado por el recién formado Centro Dom Vital. Y si bien señala que "as notas sobre a inquietação moderna carecem de vigor 
e mesmo um tanto de realidade", y no se priva de criticar el portugués del libro, reconoce sin embargo a su autor como "um dos mais notáveis filósofos do Brasil” (G. de N., 1922: 12-13).

A lo largo de la revista, las reseñas más extensas y detalladas corresponden a las obras incluidas, directa o indirectamente, en la "familia de Klaxon", como es el caso del libro Le Miracle de vivre de Charles Baudoin, que aparece ya desde el primer número como representante de la revista en Suiza, o los Epigrammas irônicos e sentimentais de Ronald de Carvalho, la propia Paulicéia Desvairada de Mário (que reseña Tácito de Almeida, bajo el seudónimo de Carlos Alberto de Araujo), Os Condemnados de Oswald de Andrade (reseñado por Couto de Barros), y el libro O homem e a morte, de Menotti Del Picchia, a cargo de Mário en el último número. Con el pretexto de presentar una lectura sobre esta obra, Mário comienza realizando una especie de "balance del modernismo", inscribiendo en una misma serie a Roland, Menotti, Oswald y Guilherme de Almeida -cuyo libro, As canções gregas, todavía no había aparecido, pero este es un detalle que no le impide a Mário incluirlo en el espectro de obras que, a su juicio, muestran ya claramente la consolidación del grupo:

O movimento revolucionário artístico que se acentuou, ha coisa de 2 anos, com a definitiva feição tomada por certos moços de S. Paulo, teve seu Messidor neste ano do Centenário. Ronald de Carvalho deu-nos, no Rio, seus "Epigrammas Irônicos e Sentimentais", Oswaldo de Andrade apresentou "Os Condenados". Agora é a vez de Menotti Del Picchia com "O homem e a morte". Lastimo sinceramente que "As canções gregas" de Guilherme de Almeida não possam aparecer ainda este ano. A tetratologia completa das grandes obras que modificarão certamente a fisionomia das letras indígenas teria aparecido no período fechado dum ano; e bem poderíamos em 2022 celebrar $\mathrm{o} 1^{\circ}$ Centenário de nossas independência literária. E digo "independência" pensadamente, certo do que digo: embora saiba que estas obras claramente se ligam a feições modernas da literatura universal. -Então é dependência!- Não. Antigamente imitávamos a literatura francesa com uma distância de mais ou menos duas gerações. Agora estamos com o presente da literatura universal. Não é mais seguir. É ir junto. Não é imitar. É coadjuvar. Independência pois (M. de A. 1922-23: 27-29). 
Mário presenta las obras de Ronald, Menotti, Oswald y Guilherme -notoriamente diferentes entre sí- como partes de un mismo movimiento que aspira a superar el "atraso" de la producción brasileña, acompañando las tendencias contemporáneas de la literatura universal. Pero tanto las cartas de Mário a Tarsila como el testimonio posterior de Rubens Borba de Moraes a Aracy Amaral sugieren que esta imagen que unifica al grupo, en realidad es el resultado de un consenso atravesado por conflictos y peleas internas.

En efecto, Mário le explica a Tarsila que Oswald, posiblemente irritado por las observaciones críticas de Mário con respecto a su novela:

Um dia irrompe pelo escritório da Klaxon. Vem temeroso e furibundo. 'O Mário é isto, mais aquilo. Quer ser chefe de escola. Nós todos seus alunos! É preciso romper. É o pior critico do mundo! Vocês todos estão ficando escravos dele. Não me sujeito! Nem o Menotti. O Mário disse que vai decorar, para dizer, as últimas páginas do Homem e a morte... Isso é caçoada' (AMARAL, 1999: 72).

Oswald, seguramente molesto por la opinión disciplicente sobre Os Condenados, inventa -según la versión de Mário- esa historia de que nuestro autor pretendería ridiculizar a Menotti, recitando de memoria las últimas páginas de la novela $O$ homem $e$ a morte.

Entretanto, en la redacción de Klaxon, Tácito de Almeida, Couto de Barros y Rubens Borba de Moraes habían escrito una crítica fuerte contra el libro de Menotti, acusándolo de danunziano y "passadista”. Según el testimonio de Rubens:

O artigo estava pronto para ser publicado quando chega o Mário. Leu o artigo. Disse que absolutamente não poderia ser publicado. Que deveríamos respeitar a personalidade de Menotti pelo que ele significa para o movimento, seu prestígio a serviço da causa, etc. Foi uma grande discussão e briga. Mário então disse-nos que ele ia escrever outro artigo substituindo aquele. No dia seguinte, ou dois dias depois, ele apareceu na redação com o artigo sobre $\mathrm{O}$ homem e a morte: um elogio só, a exaltação do livro. O momento de fúria foi então nosso. Finalmente Mário acedeu a que revisássemos o artigo, diminuindo um pouco o calor do elogio. O que fizemos riscando aqui e ali. $\mathrm{E}$ esse foi o artigo finalmente publicado, e por essas razões (Apud AMARAL, 2003: 61). 
Es cierto que, en conjunto, la parte de la reseña dedicada al libro de Menotti parece- como dice Rubens- "um elogio só", pero en las entre líneas, encubiertas o disimuladas por el juicio francamente laudatorio del libro, es posible leer un conjunto de restricciones que Mário le hace a Menotti. Así, por ejemplo, no se priva de subrayar que el estilo es "duma verborragia altisonante e eloquente" que resulta cansativa; o que podría citarse a su favor a Max Jacob, "uno de esos modernistas franceses" que Menotti ridiculiza "livianamente" en sus crónicas porque jamás los leyó. Es decir, si Mário quiere mostrar que a partir de la intervención del grupo formado en Klaxon la producción literaria brasilera ya no se encuentra en desfasaje con el presente de la producción universal, el libro que elige para mostrar dicha inserción en el "espíritu de la época", paradójicamente es el que se está -como reconoce el propio Mário- más alejado de esas nuevas coordenadas, en gran parte porque Menotti las desconoce, y muchas veces emite juicios livianos sobre autores que "muito pouco leu". Claro que, por eso, Mário insinua que "a força criadora do autor" le permite saltar por sobre su propia ignorancia, pero así la nota expone el juego de malabarismo que propone el propio autor de la reseña para apuntalar un juicio positivo sobre esta obra.

Ahora, si parte del grupo veía las características "danunzianas" y "passadistas" de la novela, ciertamente estas no pasaban desapercibidas para Mário. Entonces, ¿por qué esa reseña consagratoria de una novela menor?

Porque Mário, que niega categóricamente "a intenção de criar escola", actúa como un "chefe de escola", para quien la prioridad es defender a la "familia", defender a ese grupo e instalarlo como una alternativa frente al claro predominio que todavía exhibían los circuitos de la bohemia simbolista-parnasiana. En la versión de Rubens, queda claro que Mário no acepta que la revista publique una crítica extremadamente negativa contra uno de los "camaradas" que había puesto "seu prestígio a serviço da causa".

Este será un procedimiento común en Mário. Así, en 1924, después de prometer a Manuel Bandeira un "belo estudo" sobre su poesía, a propósito de la publicación de Carnaval, cuando finalmente este sale publicado, expone en la Revista do Brasil una perspectiva crítica severa, resaltando que "de verdade o libro se compõe de mais ou menos a metade dos poemas que estão incluidos nele", porque la otra mitad quiebra la unidad emotiva del texto. Un poco estupefacto, Manuel no ahorra el reproche ante este artículo: 
Antes de entregar os meus versos à tipografia, mandei-os a você, pedindo-lhe que os criticasse: o meu desejo era que você fizesse com eles o que eu a seu pedido, faço com os seus: uma espinafração isenta de qualquer medo de magoar ou melindrar -crítica de sala de jantar de família carioca. Você tirou o corpo fora e limitou-se a aconselhar a supressão de um soneto. Se você tivesse me dado outros conselhos, o meu livro sairia mais magro porém certamente mais belo (MORAES, 2000: 165).

Mário se apresura a responder:

Fiquei corrido de vergonha e principalmente triste. É verdade. Mas ainda eu quero comentar um pouco o caso não para me desculpar propriamente, mas pra diminuir um pouco o tamanho da falta e pra te dizer com toda a verdade da parte que se conserva pura em mim, que não fui insincero contigo. (...) Vai e fui severo demais contigo, casquei rijo, pra dar a esses gênios de vaidade um exemplo de liberdade critica, e de aceitação. Porque eu sabia que eras incapaz de ficar zangado. Forcei a nota. (...) Não fui insincero. Não deixei de ser teu amigo um segundo. Fui leviano na amizade. Isso acontece com pessoas melhores de que eu. Esquece o que te fiz (MORAES, 2000: 168).

En este caso, como en tantos otros que documenta su correspondencia, Mário reconoce que se excedió en la crítica, pero también afirma su "sinceridad", porque esta cualidad no se aplica a la opinión, sino a la intención que la crítica introduce en un contexto: más que el elogio del libro de Manuel, era prioritario dar una lección a sus amigos de libertad y aceptación crítica. En este sentido, la "sinceridad" del crítico consiste en modelar su propia opinión subjetiva a partir de una intención rectora que le da un sentido superior a ese juicio crítico, un procedimiento que podríamos considerar análogo al que propone para el poeta moderno, cuyo impulso lírico se transforma en poesía a partir del trabajo del arte, entendido como el trabajo de la inteligencia sobre el material que aporta la sensibilidad.

Y esto es lo que ocurre en la reseña sobre $O$ homem e a morte que publica en Klaxon: la crítica negativa del libro que Tácito de Almeida, Couto de Barros y Rubens de Moraes planeaban publicar era visualizada por Mário como un acto que atentaba contra los intereses generales del grupo. Exponer a Menotti como "passadista" significaba ignorar todo el apoyo desplegado a partir de sus crónicas en el Correio Paulistano, y 
ofrecer un claro flanco de ataque a toda esa "parentada" que insistía en calificarlos como provincianos imitadores de "novidadeirices".

Entonces, por un lado, contra ese grupito de Klaxon que no percibe la necesidad de resguardar esas "afinidades electivas", Mário realiza un movimiento que al mismo tiempo expone y oculta el passadismo de Menotti: exalta la "fuerza creadora" y lo manda a leer a esos modernistas franceses que - a su juicio- tan livianamente critica.

Y, por otro lado, contra la irritación de Oswald -que probablemente se sintiera desplazado de ese lugar tácito de "chefe de escola"-, Mário produce una reseña que muy probablemente, en ese contexto, inclinara a Menotti a reconocer su liderazgo, condición que curiosamente en la reseña se afirma implícitamente por la negación, cuando tira a Paulicéia Desvairada del cuadro que construye esa "tetralogía":

Alguns pensarão que, por modestia, não citei "Paulicéia Desvairada"... Não citei, porquê não devia citar. "Paulicéia" (como aliás imagino que será toda a minha obra) tem um aspecto tão especial, tão desvariado, tão extra, que não pode ter um efeito plausível numa renovação. Seu caráter selvagem, orgulhosamente pessoal, tira-lhe essa expressão de humanidade, de coisa universal, cósmica, que permite desenvolvimento e assimilação. É uma obra á parte (M. de A., 1922-23: 27).

Si Paulicéia está aparte, es porque también Mário está aparte. Efectivamente, no es la modestia lo le impide sumar a su libro a esa lista que muestra ya la "apariencia definitiva" tomada por "ciertos jóvenes de San Pablo", sino su condición -todavía implícita- de líder y maestro del grupo, que emerge convocada e impugnada por amigos y adversarios.

Ya en la reseña de Paulicéia Desvairada, publicada en el número 7, Tácito de Almeida (bajo el seudónimo de Carlos Alberto de Araujo), señala que en la crítica exasperada a la figura del burgués puede leerse un rasgo de "bondade excesiva", porque "só os homens excessivamente bons é que se preoccupam com os outros e procuram plasma-los ou modifica-los á sua imagem" (Araujo, C. A. de [Tácito de Almeida], 1922, 12-14). Esta representación presenta a Mário como el pedagogo, que se preocupa por los otros y realiza el esfuerzo de educar a un público ignorante, esfuerzo que -según la perspectiva, quizás demasiada optimista, de Tácito- ya está rindiendo frutos, dado que "hoje ninguem mais se atreve a explorar a passividade do nosso publico com a pachorra 
do parnasianismo". Pero esa acción pedagógica está lejos de limitarse al público burgués: como sugiere la reacción de Oswald y se lee en las entrelíneas de la reseña de Menotti, Mário busca informar y modelar no solo al público en general y a los enemigos en particular, sino principalmente a sus propios amigos que conforman la "familia de Klaxon".

Tanto en la sección de Luzes e Refracções (desde donde Mário defiende una perspectiva cosmopolita, cuyos límites explica y defiende, frente a los "ataques" de una bohemia parnasiana-simbolista que una y otra vez busca subalternizar a estos jóvenes paulistas, dejándolos en el lugar de "provincianos"), pasando por las Chronicas sobre música o el espacio de las reseñas, el esfuerzo de Mário por seleccionar, discenir y explicar los contenidos que constituyen "lo nuevo" van de la mano de la construcción de una figura del crítico erudito, que es tan bien "maestro" y "pedagogo" del público y de sus colegas. En el período que va de 1917 a 1921, período de formación del grupo, Mário había participado relativamente poco del debate periodístico que había otorgado cierta visibilidad a estos jóvenes. Ya para 1922, la reputación del Mário de Paulicéia se afirma en Klaxón, el primer emprendimiento compartido de estos jóvenes que, como laboratorio de ideas, permitió también el aprendizaje de las estrategias de intervención, que a partir de allí se pondrán en juego en las diversas disputas por el liderazgo por las que atravesara la construcción del modernismo brasilero.

\section{Fontes}

ANDRADE, Mário de (1960 [1924]). A escrava que não é Isaura (Discurso sobre algumas tendências da poesia modernista). In: Obra Imatura. São Paulo: Martins Fontes.

(1922a). O Homenzinho que não penso. Klaxon, São Paulo, № 3, julho 15, pp. 1011.

(1922b). Guiomar Novaes I. Pianista romântica. Klaxon, № 2, junho 15, p. 13-14 (1922c). Guiomar Novaes II. A virtuose. Klaxon, SP, No 3, julho 15, 1922, p. 710.

(1974 [1942]). O movimento modernista. Aspectos da literatura brasileira. São Paulo: Martins Fontes.

(1922d). Musica. Francisco Mignone. Klaxon, SP, No 6, outubro 15, p. 12-13.

(1922e). Musica. João de Souza Lima. Klaxon, SP, No 7, novembro 15, pp. 11-12.

ARAUJO, C. A. de (Tácito de Almeida). Paulicéia Desvairada, por Mário de Andrade. Klaxon, SP, $\mathrm{N}^{\circ}$ 7, novembro 30, pp. 12-14.

A REDAÇÃO [Mário de Andrade], (1922). Klaxon. Klaxon. Mensario de Arte moderno, São Paulo, $\mathrm{N}^{\circ}$ 1, maio 15, p. 1-3. 
G. De N. [Mário de Andrade] (1922). Pascal e a inquietação moderna- Jackson de Figueiredo. In: Klaxon, SP, No 5, 15 set., pp. 12-13.

HORIGOUTCHI, Nico. (1922). A poesia japoneza contemporânea, Klaxon. São Paulo, n. 2 , jun. 15 , p. 14

Klaxon. Mensario de Arte moderna (1972 [1922]). Ed. Facsimilar. São Paulo: Livraria Martins Fonte Editora.

LUZES E REFRACÇÕES (1922a). Klaxon, São Paulo, n. 2, junho 15, pp. 16-17. (1922b). Klaxon. São Paulo, n. 3, julho 15, 1922, pp. 14-16 (1922c). Klaxon. São Paulo, n. 4, agosto 15, 1922, pp. 16-17. (1922d). Klaxon. São Paulo, n. 5, setembro 15, 1922, pp. 14-16. (1922e). Klaxon. São Paulo, n. 6, outubro 15, 1922, pp. 15-16.

M. de A. [Mário de Andrade] (1922). Luzes e Refracções. Klaxon. São Paulo, n. 1, maio 15, pp. 15-16. (1922a). Pianolatria. Klaxon, São Paulo, no 1, maio 15, 1922, p. 8. (1922-23). O homem e a morte- Menotti Del Picchia. Klaxon.São Paulo, n. 8-9, dez.-jan., pp. 27-29

\section{Referencias Bibliográficas}

AMARAL, Aracy (Org.) (1999). Correspondência Mário de Andrade \& Tarsila do Amaral. São Paulo: EDUSP-IEB.

AMARAL, Aracy (2003). Tarsila: sua obra e seu tempo. São Paulo: Editora 34/Edusp.

BRITO, Mario da Silva (1972). O alegre combate de Klaxon, Klaxon. Mensario de Arte moderna. Ed. Facsimilar. São Paulo: Livraria Martins Fonte Editora.

KOIFMAN, Georgina (org.) (1985). Cartas de Mário de Andrade a Prudente de Moraes, neto 1924-1936, Rio de Janeiro, Ed. Nova Fronteira.

LARA, Cecilia de (1972). Klaxon \& Terra Roxa e outras terras: dois periódicos modernistas de São Paulo. São Paulo: Instituto de Estudos Brasileiros.

MORAES, Eduardo Jardim de (1988). Modernismo revisitado. Estudos históricos, Rio de Janeiro, vol. 1, n 2, pp. 220-238.

MORAES, Marcos A. de (Org.) (2000). Correspondência Mário de Andrade \& Manuel Bandeira. São Paulo: EDUSP/IEB.

NAVES, Santuza C. (1998). O violão azul. Modernismo e música popular. Rio de Janeiro: Fundação Getúlio Vargas.

TRAVASSOS, Elizabeth (1997). Os mandarins milagrosos. Arte e etnografia em Mário de Andrade e Béla Bartok. Rio de Janeiro: Funarte-Jorge Zahar Editor.

Artigo recebido em 30 de agosto de 2016.

Aprovado em 01 de outubro de 2016. 